\title{
Three Cases of Gastric Antral Vascular Ectasia in Chronic Renal Failure
}

\author{
Akira Iguchi Junichiro James Kazama \\ Masamichi Komatsu Yoshikatsu Kaneko Noriaki lino \\ Shin Goto Ichiei Narita
}

Division of Clinical Nephrology and Rheumatology, Niigata University Graduate School of Medical and Dental Sciences, Niigata, Japan

\section{Key Words}

Gastric antral vascular ectasia - Hemodialysis - Chronic kidney disease - Mechanical stress . Gastric motility

\begin{abstract}
Gastric antral vascular ectasia (GAVE) is currently recognized as an important cause of gastrointestinal bleeding. Chronic kidney disease (CKD) is associated with a high incidence of GAVE. We report 3 patients with CKD who presented with severe anemia and were diagnosed with GAVE; they were resistant to endoscopic argon plasma coagulation. However, remission of anemia and improvement in GAVE lesions were observed after the initiation of hemodialysis. The pathogenesis of GAVE remains largely unknown, but mechanical stress of the antrum could play an important role. This stress may be reduced by hemodialysis through improvement of uremia-associated gastrointestinal symptoms. Therefore, the initiation of hemodialysis might be effective for intractable GAVE in CKD patients.
\end{abstract}

\section{Background}

Gastric antral vascular ectasia (GAVE) is a rare disorder associated with chronic upper gastrointestinal bleeding that mainly affects elderly women. It has a unique endoscopic appearance characterized by multiple longitudinal stripes of red vessels (watermelon stomach) or a diffuse spread of red vessels (diffuse antral vascular ectasia), which is largely limited to the gastric antrum. The typical histological findings are superficial hyperplastic gastric antral mucosa, capillary ectasia with thrombosis and fibromuscular hyperplasia in the lamina propria, and abnormal submucosal vasculature. GAVE is sometimes found in patients with chronic kidney disease (CKD), regardless of the maintenance hemodialysis

Junichiro James Kazama, MD, PhD Division of Clinical Nephrology and Rheumatology 
therapy administered. The precise reason for disease prevalence remains obscure [1]. Recently, argon plasma coagulation (APC) has been frequently used to treat GAVE [2]. However, several treatment sessions might be required.

We herein present 3 cases of GAVE associated with CKD that were not previously treated with dialysis.

\section{Case Reports}

Case 1

A 67-year-old woman with CKD stage V [serum creatinine $(\mathrm{Cr})=3.14 \mathrm{mg} / \mathrm{dl}$; eGFR $=12.3$ $\mathrm{ml} / \mathrm{min} / 1.73 \mathrm{~m}^{2}$ ] caused by biopsy-proven chronic mesangial proliferative glomerulonephritis suffered from loss of appetite and edema with uremia. Laboratory findings showed severe anemia [hemoglobin $(\mathrm{Hb})=5.8 \mathrm{~g} / \mathrm{dl}$ ] despite treatment with recombinant human erythropoietin (rHuEPO) and intravenous iron administration. Liver function was normal. Upper gastrointestinal endoscopy showed watermelon stomach at the antrum without active bleeding. Despite repeated blood transfusions, severe anemia was sustained. Six months later, the patient was treated with APC, but the anemia persisted. One month after the first APC administration, a second round of APC treatment was administered, and hemodialysis therapy was initiated (ig. 1). Thereafter, her anemia improved, and no additional transfusions have since been performed.

\section{Case 2}

A 61-year-old woman with alcoholic liver cirrhosis (Child-Pugh class B) and CKD stage $\mathrm{V}(\mathrm{Cr}=3.14$ $\mathrm{mg} / \mathrm{dl}$; eGFR $=12.6 \mathrm{ml} / \mathrm{min} / 1.73 \mathrm{~m}^{2}$ ) caused by hepatorenal syndrome was admitted to the hospital. She suffered from loss of appetite with uremia and had severe anemia $(\mathrm{Hb}=4.8 \mathrm{~g} / \mathrm{dl})$ despite administration of rHuEPO and intravenous iron. She also had severe melena, and upper gastrointestinal endoscopy revealed diffuse antral vascular ectasia without esophageal varices or active bleeding. She was treated with APC twice, but frequent blood transfusions were required. Five months after the second APC treatment, the patient was started on hemodialysis because of volume expansion (fig. 1). After the initiation of hemodialysis, her appetite improved and the melena disappeared. She no longer requires blood transfusions.

\section{Case 3}

A 66-year-old woman with CKD stage $\mathrm{V}\left(\mathrm{Cr}=6.4 \mathrm{mg} / \mathrm{dl}\right.$; eGFR $\left.=5.7 \mathrm{ml} / \mathrm{min} / 1.73 \mathrm{~m}^{2}\right)$ presented with severe anemia $(\mathrm{Hb}=4.8 \mathrm{~g} / \mathrm{dl})$ and suffered from lassitude, loss of appetite, and dyspnea with uremia. The primary cause of CKD was an autosomal dominant polycystic disease with numerous and massive cysts in both the kidneys and liver. Her anemia was resistant to $\mathrm{rHuEPO}$ and intravenous iron treatment. Liver function was normal. Upper gastrointestinal endoscopy showed watermelon stomach. Although APC was administered twice, severe anemia persisted. After 8 months of APC sessions, she was treated with another round of APC and started on hemodialysis (fig. 1). After the induction of hemodialysis, her loss of appetite and lassitude disappeared. Moreover, her anemia improved, and GAVE has not recurred.

Written informed consent was obtained from all 3 patients.

\section{Discussion}

GAVE is often associated with systemic illnesses such as cirrhosis of the liver, autoimmune connective tissue disorders, bone marrow transplantation, and CKD [3]. 
APC is a standard therapy for GAVE. However, most patients require several sessions to achieve the desired clinical benefits.

Although the pathogenic link remains unclear, vascular ectasia is a significantly more common cause of upper gastrointestinal bleeding in patients with CKD than in those with normal renal function (13 vs. $1.3 \%$, respectively; $\mathrm{p}<0.01$ ) [4].

The pathogenesis of GAVE is not well understood. Antral motility studies showed an abnormal pattern in patients with GAVE and cirrhosis [5]. It has been reported that the antral area half-time in these patients is significantly increased when compared with that of healthy controls. This finding supports the idea that mechanical stress plays an important role in the pathogenesis of GAVE. In patients with CKD, increased mechanical stress of the antrum in uremia-induced weakening of gastric emptiness is thought to contribute to the development of GAVE.

According to another theory, vasoactive mediators have an important pathogenic role in GAVE. Enhanced gastrin levels, which are known to increase gastric vasodilation, have been observed in patients with GAVE. However, the pathogenic role of gastrin is not supported by all studies because hypergastrinemia is not invariably present in patients with GAVE. Prostaglandin E2 is another hormone with vasoactive functions; in a single study, it was found to be significantly higher in cirrhosis patients with GAVE than in those without. In another study, histological examination showed that neuroendocrine cells containing 5-hydroxytryptamine and vasoactive intestinal peptide were found close to the ecstatic gastric mucosal vessels [6-8]. Disturbed renal excretion and/or catabolism of these vasoactive mediators in patients with CKD might also be associated with GAVE.

Uremia-induced platelet dysfunction might also be incriminated as a risk factor for antral bleeding [9]. Volume overload has not been reported to be associated with GAVE, which is sometimes confused with portal hypertensive gastropathy. Indeed, portal hypertensive gastropathy is associated with portal hypertension and congestive heart failure. However, GAVE did not improve with treatment for portal hypertension and congestive heart failure because intra-abdominal venous pressure was not necessarily parallel with circulating volume [10]. Moreover, it was reported that GAVE in a patient with end-stage renal disease improved following a change to continuous ambulatory peritoneal dialysis from hemodialysis [11]. Therefore, volume overload may not be associated with GAVE.

In the 3 patients with CKD reported in this study, the development of severe anemia was obviously associated with GAVE before the initiation of hemodialysis, and the patients required frequent blood transfusions despite APC therapy (fig. 1). None of the 3 patients experienced a relapse of GAVE after the initiation of hemodialysis. Interestingly, all of the patients experienced severe loss of appetite, and gastrointestinal symptoms disappeared with the initiation of hemodialysis. It was reported that hemodialysis might improve impaired gastric motility and reduce gastrointestinal symptoms in patients with chronic renal failure [12]. Therefore, the improvement in upper gastrointestinal motility is assumed to have resulted in the improvements in appetite and GAVE. In addition, the resolution of GAVE due to the improvement in gastric motility may have resulted in further appetite increase.

A single endoscopic examination often fails to identify GAVE, which may be a more common complication among patients with end-stage renal disease than is generally 
considered. It is known that a number of patients, even those undergoing dialysis, have severe anemia due to GAVE. In these patients, GAVE might be associated with multiple factors. However, mechanical stress in the antrum due to underdialysis might be one of the causes. In such cases, improvement in dialysis efficiency might contribute to the remission of GAVE.

Actually, some cases of GAVE recur after several years. But there have been no reports on the recurrence of GAVE with hemodialysis. According to our theory, a recurrence of GAVE after the initiation of hemodialysis should be a rare event. However, we need longer follow-up periods for these patients, because the follow-up periods for our 3 patients (2-8 months) would certainly be considered short. We conclude that initiation of dialysis may induce the remission of intractable GAVE in patients with CKD. Although the cause is still unknown, improvement in uremia-induced mechanical stress in the antrum might contribute to the remission of GAVE. We suggest that in patients with renal insufficiency who suffer from GAVE relapse, it is important to introduce dialysis treatment.

\section{Disclosure Statement}

The authors report no conflicts of interest.

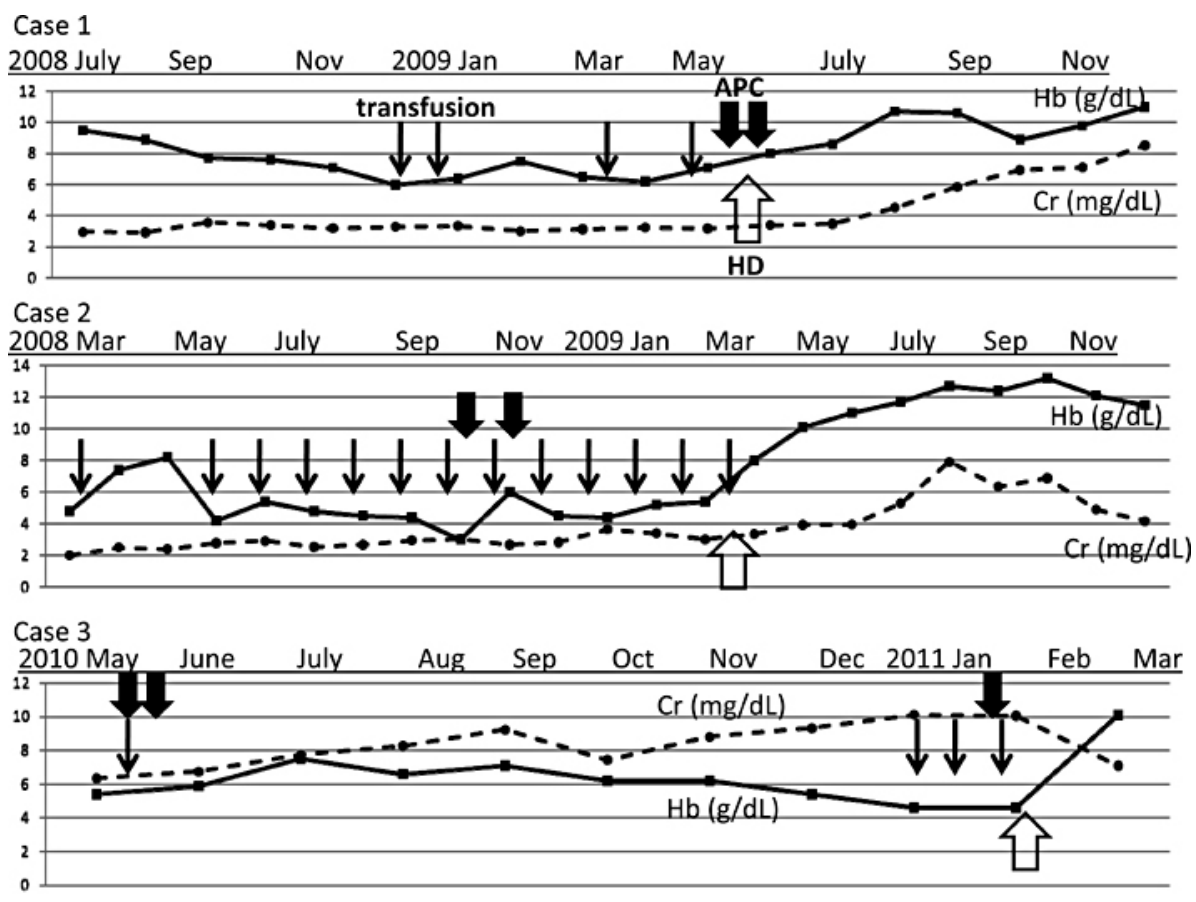

Fig. 1. Clinical course of each of the 3 cases of GAVE concomitant with chronic renal failure. $\mathrm{HD}=$ Hemodialysis. 


\section{References}

1 Navab F, Masters P, Subramani R, Ortego TJ, Thompson CH: Angiodysplasia in patients with renal insufficiency. Am J Gastroenterol 1989;84:1297-1301.

2 Komiyama M, Fu K, Morimoto T, Konuma H, Yamagata T, Izumi Y, Miyazaki A, Watanabe S: A novel endoscopic ablation of gastric antral vascular ectasia. World J Gastrointest Endosc 2010;2:298-300.

3 Selinger CP, Ang YS: Gastric antral vascular ectasia (GAVE): an update on clinical presentation, pathophysiology and treatment. Digestion 2008;77:131-137.

4 Chalasani N, Cotsonis G, Wilcox CM: Upper gastrointestinal bleeding in patients with chronic renal failure: role of vascular ectasia. Am J Gastroenterol 1996;91:2329-2332.

5 Charneau J, Petit R, Cales P, Dauver A, Boyer J: Antral motility in patients with cirrhosis with or without gastric antral vascular ectasia. Gut 1995;37:488-492.

6 Quintero E, Pique JM, Bombi JA, Bordas JM, Sentis J, Elena M, Bosch J, Rodes J: Gastric mucosal vascular ectasias causing bleeding in cirrhosis. A distinct entity associated with hypergastrinemia and low serum levels of pepsinogen I. Gastroenterology 1987;93:1054-1061.

7 Lowes JR, Rode J: Neuroendocrine cell proliferations in gastric antral vascular ectasia. Gastroenterology 1989;97:207-212.

8 Saperas E, Perez Ayuso RM, Poca E, Bordas JM, Gaya J, Pique JM: Increased gastric PGE2 biosynthesis in cirrhotic patients with gastric vascular ectasia. Am J Gastroenterol 1990;85:138-144.

9 Stefanidis I, Liakopoulos V, Kapsoritakis AN, Ioannidis I, Eleftheriadis T, Mertens PR, Winograd R, Vamvaka E, Psychos AK, Potamianos SP: Gastric antral vascular ectasia (watermelon stomach) in patients with ESRD. Am J Kidney Dis 2006;47:e77-e82.

10 Spahr L, Villeneuve JP, Dufresne MP, Tasse D, Bui B, Willems B, Fenyves D, Pomier-Layrargues G: Gastric antral vascular ectasia in cirrhotic patients: absence of relation with portal hypertension. Gut 1999;44:739-742.

11 Yorioka N, Hamaguchi N, Taniguchi Y, Asakimori Y, Nishiki T, Oda H, Yamakido M: Gastric antral vascular ectasia in a patient on hemodialysis improved with CAPD. Perit Dial Int 1996;16:177-178.

12 Adachi H, Kamiya T, Hirako M, Misu N, Kobayashi Y, Shikano M, Matsuhisa E, Kataoka H, Sasaki M, Ohara $\mathrm{H}$, Nakao H, Orito E, Joh T: Improvement of gastric motility by hemodialysis in patients with chronic renal failure. J Smooth Muscle Res 2007;43:179-189. 